\title{
Intra-list interference in single trial short-term memory ${ }^{1}$
}

DONALD A. SCHUMSKY, ANTHONY F. GRASHA, ERHARD O. EIMER AND JOHN TRINDER UNIVERSITY OF CINCINNATI

In a group testing procedure, 480 Ss wer' given a single trial to learn a list of five nonsense syllables, presented one at a time in order. Ss were given an interpolated interval of 0,15 , or $30 \mathrm{sec}$ in which they were required to cancel vowels from lists of random letters. At the end of the interval they were required to recall either the first, middle, or last syllable in the list. Results revealed a significant effect associated only with serial position.

When first presented, experiments in short term memory were considered to be minimal memory experiments. Presentation of a single to-be-recalled stimulus and requiring $\mathrm{Ss}$ to make a unitary recall of that single stimulus after a few seconds seemed the minimal possible arrangement for the study of memory. Thus, when these studies yielded data showing retention losses after such short retention intervals, the presence of a distinct short term memory process was inferred. In addition, memory losses seemed not attributable to the action of traditional interference variables (retroactive and proactive inhibition), and this short term memory process was conceived as a trace decay process.

In 1962, Keppel and Underwood demonstrated that retention loss in short term memory was related to ordinal position within a series of such short term memory tests. This and other studies (cf., Loess, 1964; Wickens, Born, \& Allen, 1963) have made it clear that short term memory experiments as usually conducted were not "minimal." That is they represented multi-trial, multi-test designs. Retention when studied on the nth trial was not independent of previous tests and was different from retention as studied on the first test trial.

To properly assess the action of a short term memory process the appropriate experimental design would require a truly minimal memory experiment. This must be a one-trial, single test of short term memory. The present experiment is designed as such a test. Ss were given a single presentation of a verbal list and were required to recall one selected item from that list in a short term memory design. In this way the relative contribution to retention loss of interference factors due to list position was assessed against the effect of interval per se.

Method

The Ss were 480 undergraduate students. The basic design was a three by three factorial with each cell defined by the conditions of recall. The two variables were the serial position of the recalled item, either the first, third, or fifth item from a previously pre- sented list, and the retention interval at which recall was required, either 0,15 , or $30 \mathrm{sec}$. Three replications were performed to allow for the experimental confounding of specific test syllable over ordinal position. The experiment employed a group testing procedure. Each group test represented one of the 27 cells from the experimental design as described above.

After being seated in the experimental room, each $S$ was given a sheet of paper, face down, on which rows of random letters were printed. At the bottom of this page was a small rectangle within which $\mathrm{S}$ was to write his recall response. Ss were told that they were taking part in an experiment to study their ability to concentrate, and that this ability would be assessed by determining how well they could check vowels from random strings of letter while being required to remember something. They were told that a list of five nonsense syllables (High $\mathrm{M} \mathrm{CVCs}$ from the Glaze list) would be presented one at a time. They were to memorize these items in order, and told that after a period of rowel checking they would be asked to write all or some part of the list.

Stimuli were presented visually one at a time each for 2 sec. A slide with the word "ready" appeared on the wall to start the trial. This was followed immediately by the five list items. Following the last CVC was a slide with five dots. This was S's signal to turn over his sheet of paper and start checking vowels as "quickly and as accurately as possible." After the appropriate retention interval, $E$ commanded S to "stop" checking vowels and indicated which stimulus $S$ was to recall by saying "write the first (third or fifth) word in the box at the bottom of the page."

\section{Results}

The main findings of this experiment are presented as Fig. 1. Presented is the percent correct recall for each serial position tested, first (1), third (3), or fifth (5) as a function of retention interval after combining all three replications. Due to the group testing procedure these data points were based on from 45 to $58 \mathrm{Ss}$.

As can be seen in Fig. 1 there is little evidence for a retention loss over the $30 \mathrm{sec}$ retention interval. However, rather strong effects on retention seem to be discernible as due to serial position. The major effect of serial position seems to be associated with primacy, and therefore the retention loss would seem to be due to proaction.

Each of the 27 groups was treated as a single data 


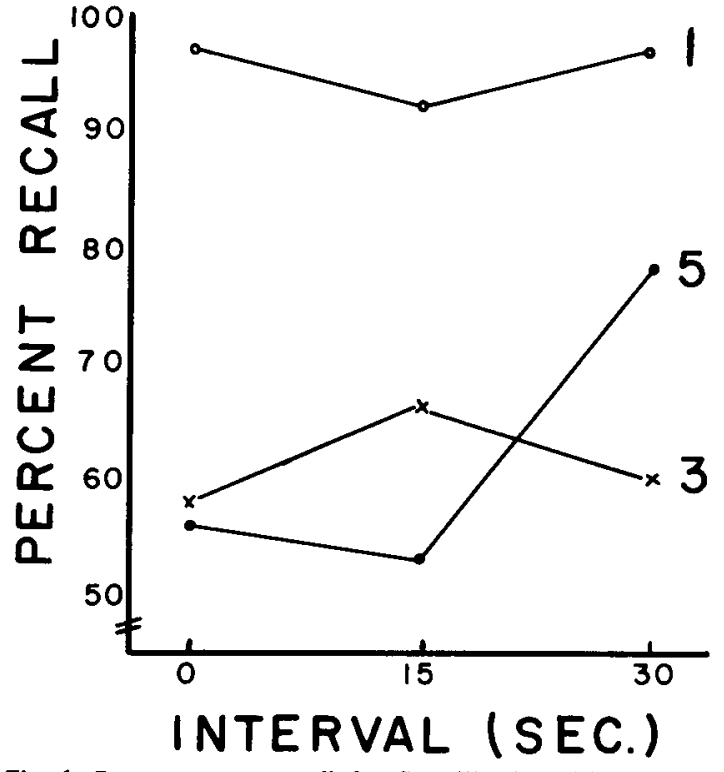

Fig. 1. Percent correct recall for first (1), third (3) or fifth (5) serial position as a function of retention interval.

point for statistical analysis. After performing an arcsin transformation on the percent correct recall for each group, the data were subjected to an analysis of variance. The results of this analysis revealed a significant main effect associated with serial position $(F=35.25, d f=2 / 18, p<.01)$. Neither the mean square associated with the interval main effect ( $F$ =2.07, $\mathrm{df}=2 / 18$ ) nor the interaction of interval and serial position ( $F=1.53, d f=4 / 18$ ) was statistically significant.

One other interesting effect is revealed in the data. There is an increase in percent recall of the fifth syllable at the $30 \mathrm{sec}$ retention interval when compared with recall of the same serial position at 0 and 15 sec. This is not unlike an effect reported by Peterson (1966) which he identified as reminiscence.

\section{Discussion}

The results of the present experiment support an interference explanation of short term forgetting. The only effective independent variable in this experiment was serial position. No loss of retention due to retention interval per se was found and therefore no comfort is provided for theorists presenting a trace decay view of short term memory. If there is any effect of time, it is a tendency toward improved recall after $30 \mathrm{sec}$, an effect similar to that described as reminiscence (Peterson, 1966). The findings of the present experiment are generally consonant with the few other studies presenting data on one-trial recall in short term memory (Goggin, 1966; Keppel \& Underwood, 1962; Rohrman \& Jahnke, 1965). It is difficult to see how a trace view could be made con- sonant with such data unless the trace decay process is hypothesized as operating under conditions not met by the present experiment but which have obtained in other short term memory experiments. There are two possibilities. Perhaps the decay process is only activated when an overload occurs in the short term memory store or the decay process is in some way set in motion only after proactive priming as provided by a series of memory tests. Clearly, an ultimate choice between views will never be made by experiment until unequivocal operational distinctions can be drawn.

The findings associated with serial position might be somewhat surprising. That is, one would expect a bow shaped serial position effect if one were to extrapolate from the list learning literature. Though $S$ was required to learn a list in order, he was not tested by being asked for a complete reproduction of the list. Rather, after going through the list once, he responded with a single item when cued by serial position as a stimulus. Examination of the literature revealed no instance of the previous use of this procedure. Most analogous is Murdock's (1961) experiment where $S$ learned a paired associate list and was cued for single item recall by the $S$ from the S-R pair. If one conceptualizes ordinal serial position as the $S$ from the $S-R$ pair in the present experiment, the technique seems quite similar. Unfortunately, Murdock does not report results from a five item list for comparison. In addition, though the Murdock data are not in conflict with the present findings, his report presents results after summing a prolonged ordinal series of test trials. It would seem that support for the generality of the present finding must rest upon the large $\mathrm{N}$ employed and verification by further research.

\section{References}

GOGGIN, J. Retroactive and proactive inhibition in the short-term retention of paired associates. J. verbal Learn. verbal Behav., 1966, 5 , 526-535.

KEPPEL, G., \& UNDERWOOD, B. J. Proactive inhibition in short-term retention of single items. J. verbal Learn. verbal Behav., 1962, 1, 153-161.

LOESS, H. Proactive inhibition in short-term memory. J. verbal Learn. verbal Behav., 1964, 3, 362-368.

MURDOCK, B. B., Jr. The retention of individual items. $J$. exp. Psychol., 1961, 62, 618-625.

PETERSON, L. R. Reminiscence in short-term retention. J. exp. Psy. chol., 1966, 71, 115-118.

ROHRMAN, N. L., \& JAHNKE, J. C. Effect of recall condition, presentation rate and retention interval on short-term memory. Psychol. Rep., 1965, 16, 877-883.

WICKENS, D. D., BORN, D. G., \& ALLEN, C. K. Proactive inhibition and item similarity in short-term memory. $J$. verbal Learn. verbal Behav., 1963, 2, 440-445.

Note

1. A report based on these data was made to the 1967 Midwestern Psychological Association meeting. 